\title{
From Paris and Shanghai to Singapore: A Multidisciplinary Study in Evaluating the Provenance and Dating of Two of Liu Kang's Paintings
}

\author{
Damian Lizun ${ }^{*}$ \\ Heritage Conservation Centre, National Heritage Board, 32 Jurong Port Rd, 619104, Singapore, Republic of Singapore
}

Received June 18, 2021

Revised July 19, 2021

Accepted July 22, 2021

*Corresponding author

E-mail: damian_lizun@nhb.gov.sg,

d.lizun@fineartconservation.ie

Phone: +6562672656

Journal of Conservation Science 2021;37(4):322-339

https://doi.org/10.12654/JCS.2021.

37.4 .02

pISSN: 1225-5459, eISSN: 2287-9781

(c) The Korean Society of Conservation Science for Cultural Heritage

This is an Open-Access article distributed under the terms of the Creative Commons Attribution Non-Commercial License (http://creativecommons.org/ licenses/by-nc/3.0) which permits unrestricted non-commercial use, distribution, and reproduction in any medium, provided the original work is properly cited.

\begin{abstract}
This paper focuses on the dating and provenance of two paintings, Climbing the hill and View from St. John's Fort by the prominent Singaporean artist Liu Kang (1911-2004). Climbing the hill, from the National Gallery Singapore collection, was believed to have been created in 1937, based on the date painted by the artist. However, a non-invasive examination unveiled evidence of an underlying paint scheme and a mysterious date, 1948 or 1949. These findings prompted a comprehensive technical study of the artwork in conjunction with comparative analyses of View from St. John's Fort (1948), from the Liu family collection. The latter artwork is considered to be depicting the same subject matter. The investigation was carried out with UVF, NIR, IRFC, XRR, digital microscopy, PLM and SEM-EDS to elucidate the materials and technique of both artworks and find characteristic patterns that could indicate a relationship between both paintings and assist in correctly dating Climbing the hill. The technical analyses were supplemented with the historical information derived from the Liu family archives. The results showed that Climbing the hill was created in 1948 or 1949 on top of an earlier composition painted in Shanghai between 1933 and 1937. As for the companion View from St. John's Fort from 1948, the artist reused an earlier painting created in France in 1931. The analytical methods suggested that Liu Kang used almost identical pigment mixtures for creating new artworks. However, their painting technique demonstrates some differences. Overall, this study contributes to the understanding of Liu Kang's painting materials and his working practice.
\end{abstract}

Key Words Liu Kang, SEM-EDS, IRFC, Painting supports, Hidden paintings, Authenticity, Pigments

\section{BACKGROUND}

Liu Kang (1911-2004) is recognised as a foremost Singaporean pioneer artist. He was born in Yongchun, Fujian province, China. He obtained an art education at the Xinhua Arts Academy in Shanghai in 1928 and continued his art studies at the Académie de la Grande Chaumière in Montparnasse in Paris, where he stayed from 1929 to 1932. During that time, Liu Kang painted intensively, and his technique reflects the influences of the Impressionist, Post-Impressionist and Fauvist styles he studied during museum and gallery visits (Kwok, 2000). He accepted the post of Professor at the Shanghai Art Academy in 1933, and continued teaching and painting until 1937, when the Second
Sino-Japanese War (1937-1945) broke out. Forced to move to Malaya, he struggled to develop artistically due to poor living conditions during the Japanese Occupation (19411945). The scarcity of oil paints encouraged his practice of pastels keep the creative spark alive. Mao's victory in 1949 and the communists' demand for Chinese artists to adhere to the party line on art probably discouraged Liu Kang from returning to China (Croizier, 1993). Therefore, he decided to relocate permanently to Singapore in 1945. Liu Kang taught art in various schools, offered weekend private art tuition and designed cinema posters and adverts. Despite his demanding work schedules, he managed to find the time for his passion and continued painting during trips across Malaya. Liu Kang's works developed during that period differ 
significantly from those created in Paris and Shanghai suggesting that he was pursuing the quest of developing his own painting style (Liu, 1997).

Climbing the hill (1937) from the National Gallery Singapore (NGS) is an oil-on-canvas painting measuring $75 \times$ $61 \mathrm{~cm}$. It depicts St. John's Fort in Malacca, Malaysia (Figure 1a). According to the painted date, the painting was created just after Liu Kang's arrival to Malaya. An analysis of this artwork could give insights into the painting materials Liu Kang used during the war, while he was situated in a remote area and far from the art suppliers. However, the initial non-invasive examination of the paint layer revealed losses showing an underlying paint scheme, another signature by Liu Kang and an intriguing, later, date, which appeared to be 1948 or 1949. These findings extended the objective of the investigation into the provenance and dating of Climbing the hill. A comprehensive comparative technical study with another painting from 1948 seemed the best approach to verify the dating. Thus, View from St. John's Fort in the collection of the Liu family was selected for the comparative analyses (Figure 1c). The painting is oil-on-canvas, measuring $46 \times 55 \mathrm{~cm}$. The relationship between both paintings has never been debated as View from St. John's Fort had probably been considered by the artist as less successful and thus never exhibited. Both paintings appeared to have been created at the exact location, albeit
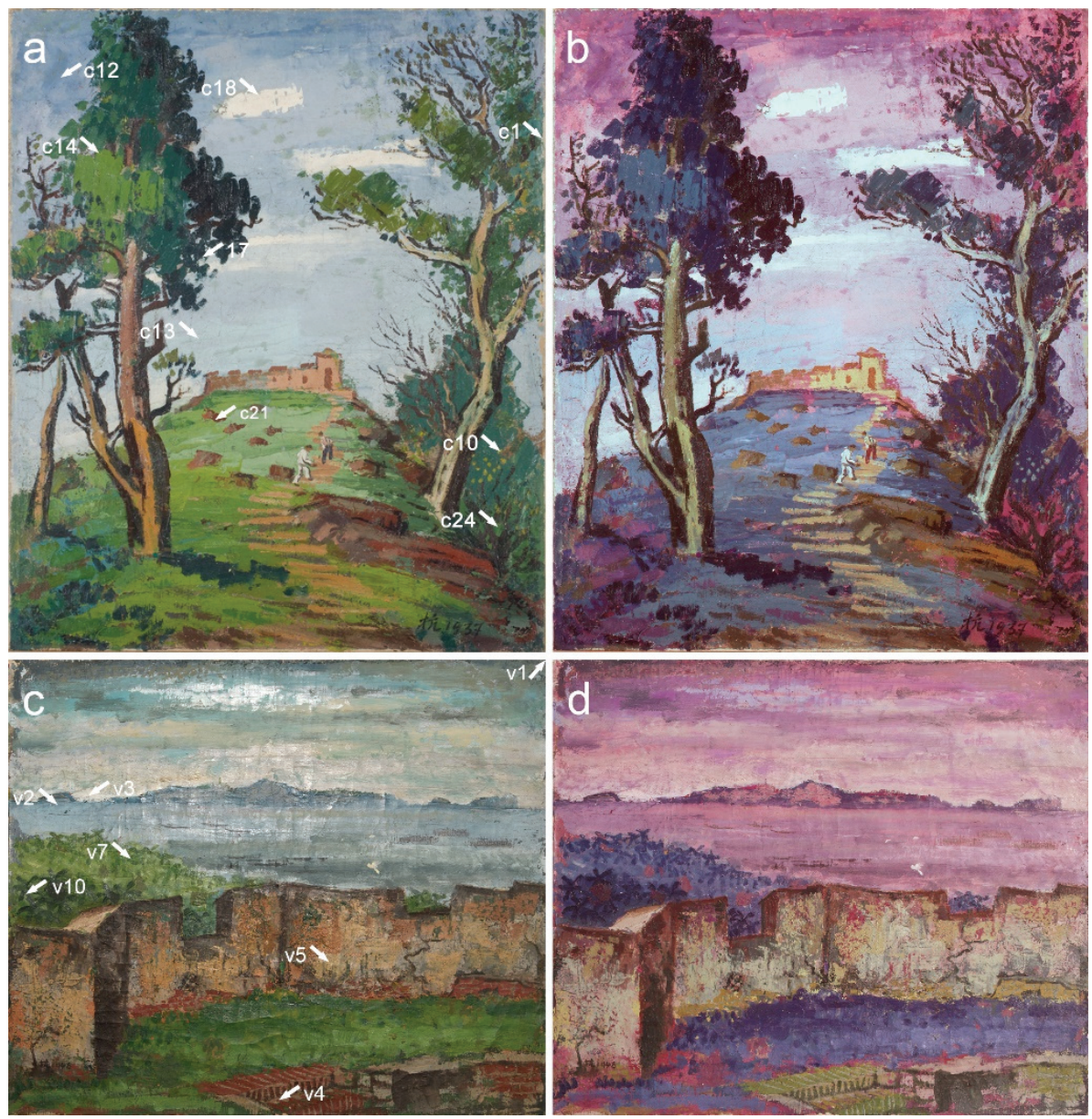

Figure 1. Liu Kang, Climbing the hill, 1937, oil on canvas, $75 \times 61 \mathrm{~cm}$, photographed in (a) VIS and (b) IRFC image. Gift of the artist's family. Collection of National Gallery Singapore. Image courtesy of National Heritage Board. White arrows indicate sampling areas. Liu Kang, View from St. John's Fort, 1948, oil on canvas, $46 \times 55 \mathrm{~cm}$, photographed in (c) VIS and (d) IRFC image. Liu Kang Family Collection. Images courtesy of Liu family. White arrows indicate sampling areas. 
captured from different observation points. Climbing the hill is a vertical and symmetrical composition showing St. John's Fort in the central focal point on top of the hill. The main subject is framed by trees on the left and right. View from St. John's Fort is a horizontal composition depicting the fort's defence walls and an open view of the Malacca Strait towards the distant hills of Pulau Besar island. Moreover, an initial inspection of the painting revealed the presence of an underlying paint scheme. As both paintings appeared to be created over earlier compositions, it was crucial to cross-reference the analytical data obtained from the investigated artworks with the research results of Liu Kang's painting supports from his Paris (1929-1932) and Shanghai (1932-1937) artistic phases (Lizun et al., 2021b). Moreover, some references were made to the earlier research about Liu Kang's painting practice (Lizun, 2020; Lizun et al., 2021a; Lizun et al., 2021c). An additional insightful search of the Liu family archives provided unexpected evidence, which combined with the analytical techniques, assisted in determining the provenance and dating of Climbing the hill.

\section{METHODS}

The paintings were first investigated by means of non-invasive methods. Technical data was collected from both paintings, including the artworks dimensions and the characteristics of the textile supports, like the weave, density and twist of threads. Technical photography included visible light (VIS), ultraviolet fluorescence (UVF), and near-infrared (NIR), the objective being to record the condition of the paintings and conduct a preliminary characterisation of the pigments for guiding further in-depth analyses. A digital microscopy, X-ray radiography (XRR) and NIR imaging were carried out to determine the evidence of underlying paint layers. As View from St. John's Fort had to be examined in-situ, at the Liu family premises, it was not selected for the XRR. Then, the samples of the paint layers were extracted and studied using optical microscopy (OM), polarised light microscopy (PLM) and field emission scanning electron microscope with energy dispersive spectroscopy (FE-SEM-EDS) to characterise the compositions of the paint mixtures. With regard to the textile supports, samples of fibres were extracted for morphologic identification, and staining test carried out with PLM. The data obtained from both paintings was studied to determine the presence of characteristic patterns that could assist in the verification of the provenance and dating of the Climbing the hill and confirm its relationship with View from St. John's Fort.

\subsection{Technical photography}

Paintings were photographed according to the workflow proposed by Cosentino (Cosentino, 2014; 2015; 2016) with a full-spectrum (360 to $1100 \mathrm{~nm}$ ) modified Nikon 850 DSLR camera equipped with a Nikon AF Micro NIKKOR $60 \mathrm{~mm}$ $\mathrm{f} / 2.8 \mathrm{D}$ lens. The camera was calibrated with X-Rite ColorChecker Passport and the American Institute of Conservation Photo Documentation (AIC PhD) target was used to fine-tune the white balance and exposure for the images. The images were captured in RAW format and further processed by Adobe Photoshop CC according to the standards described by the American Institute of Conservation (Warda et al., 2011).

VIS photography was performed with two $500 \mathrm{~W}$ halogen lamps and X-Nite $\mathrm{CCl}$ and $\mathrm{B}+\mathrm{W} 415$ filters coupled together and mounted on the camera lens. The same set of filters was used for the UVF imaging with the illumination system consisting of two lamps equipped with eight $40 \mathrm{~W} 365 \mathrm{~nm}$ UV fluorescence tubes. NIR imaging was performed using the same illumination system as for VIS. A Heliopan RG1000 filter was placed in front of the camera lens.

Technical photography and in particular the IRFC imaging were the useful tool for the tentative identification of the pigments and the selection of potential sampling areas. A digital editing method proposed by Cosentino (Cosentino, 2016) was carried out using Adobe Photoshop CC and included the calibration of the exposure of both the VIS and IR images with the AIC PhD target followed by the greyscale conversion of the IR image, exchange of the RGB channels between the VIS and IR images, and final alignment.

\subsection{XRR}

Climbing the hill was X-ray radiographed with a Siemens Ysio Max digital system with a detector of dimensions 35 $\times 43 \mathrm{~cm}$ and a resolution of 7 million pixels. The X-ray tube operated at $40 \mathrm{kV}$ and $0.5-2 \mathrm{mAs}$. The images were first processed with an X-ray medical imaging software, iQ-LITE, 
then exported to Adobe Photoshop CC for final alignment and merging.

\subsection{OM and PLM}

The paint samples' structure was studied in reflected VIS and UV light on a Leica DMRX polarised microscope at magnifications of x100, x200 and x400 coupled with a Leica DFC295 digital camera. PLM of pigments and morphology of fibres were carried out in transmitted VIS light at magnifications of x100, x200 and x400. PLM of pigments was conducted according to the workflow developed by Peter and Ann Mactaggart (Mactaggart and Mactaggart, 1998).

\subsection{High-resolution digital microscopy}

The surface of the paint layers and canvases were examined with a Keyence VHX-6000 digital microscope, using a zoom lens coupled with a high-speed camera. Observations were conducted at magnifications of x20-x200. For measurement analyses, a built-in Keyence software VHX-H2M2 and VHX-H4M - was used.

\subsection{FE-SEM-EDS}

The paint samples' cross-sections were mounted on carbon tapes and analysed with a Hitachi SU5000 FE-SEM coupled with Bruker XFlash ${ }^{\circledR}$ 6/60 EDS. The SEM, backscattered electron mode (BSE), was operated at $20 \mathrm{kV}$ accelerating voltage, $60 \mathrm{~Pa}$ chamber pressure, 50-60 intensity spot, and $180 \mathrm{~s}$ acquisition time. Analyses were conducted at a working distance of $10 \mathrm{~mm}$. The data acquisition and processing were performed with Bruker ESPIRIT 2.0 software.

\subsection{Staining test}

The phloroglucinol stain test was conducted on the natural fibres to determine the presence and concentration of lignin (Odegaard et al., 2000).

\subsection{Preparation of samples}

A total of 16 samples of the paint material were extracted from the areas of losses of the investigated paintings (nine samples from Climbing the hill and seven samples from
View from St. John's Fort). The sampling spots are indicated in Figure 1a, c. Additionally, two fibre samples were taken from the threads of weft and warp of each canvas. The paint samples were mounted as cross-sections in a fast-curing acrylic resin, ClaroCit from Struers (USA). The PLM pigment scrapings were prepared as slides with a Meltmount $\mathrm{nD}=1.662$ mounting medium from Cargille (USA). The samples of fibres were cleaned of contaminants by immersing them in boiled water. Then, they were mounted on microscope slides with a drop of water under the cover glass.

\section{RESULTS AND DISCUSSION}

\subsection{Non-invasive examination of Climbing the hill}

A digital microscopy of the painting's surface detected numerous paint losses in the area of the upper branches of trees, revealing a different paint scheme underneath the present composition (Figure 2). In addition, the microscopy revealed that the brushstrokes in the hidden composition were applied in different directions from those in the top paint layer. Further, XRR did not generate sufficient information about the underlying composition due to disruptions caused by a thick top paint layer, which is rich in heavy metal (Schalm et al., 2014). NIR imaging also did not aid in visualising the underlying composition, probably due to the thickness of the current paint layer. Nevertheless, the discovery of different paint scheme is not a unique occurrence in Liu Kang's artworks and is consistent with his earlier practice of reusing former paintings in Paris and Shanghai (Lizun, 2020; Lizun et al., 2021a; 2021b; 2021c).

However, the NIR photography of the bottom-left corner of the painting revealed the underlying artist's signature, a Chinese character Kang (抗), and a partially legible date in the Western style, resembling 1948 or 1949 (Figure 3a, b, c). This was a puzzling discovery as the existing artist's signature and date (1937) are in the opposite, bottom-right corner (Figure $3 \mathrm{a}, \mathrm{d}$ ). This discovery prompted the question of whether the existing signature and date (1937) are authentic and whether the underlying signature and date are part of the current composition, or belonging to a different composition that was later painted over. According to archival records, the painting was acquired as the artist's 

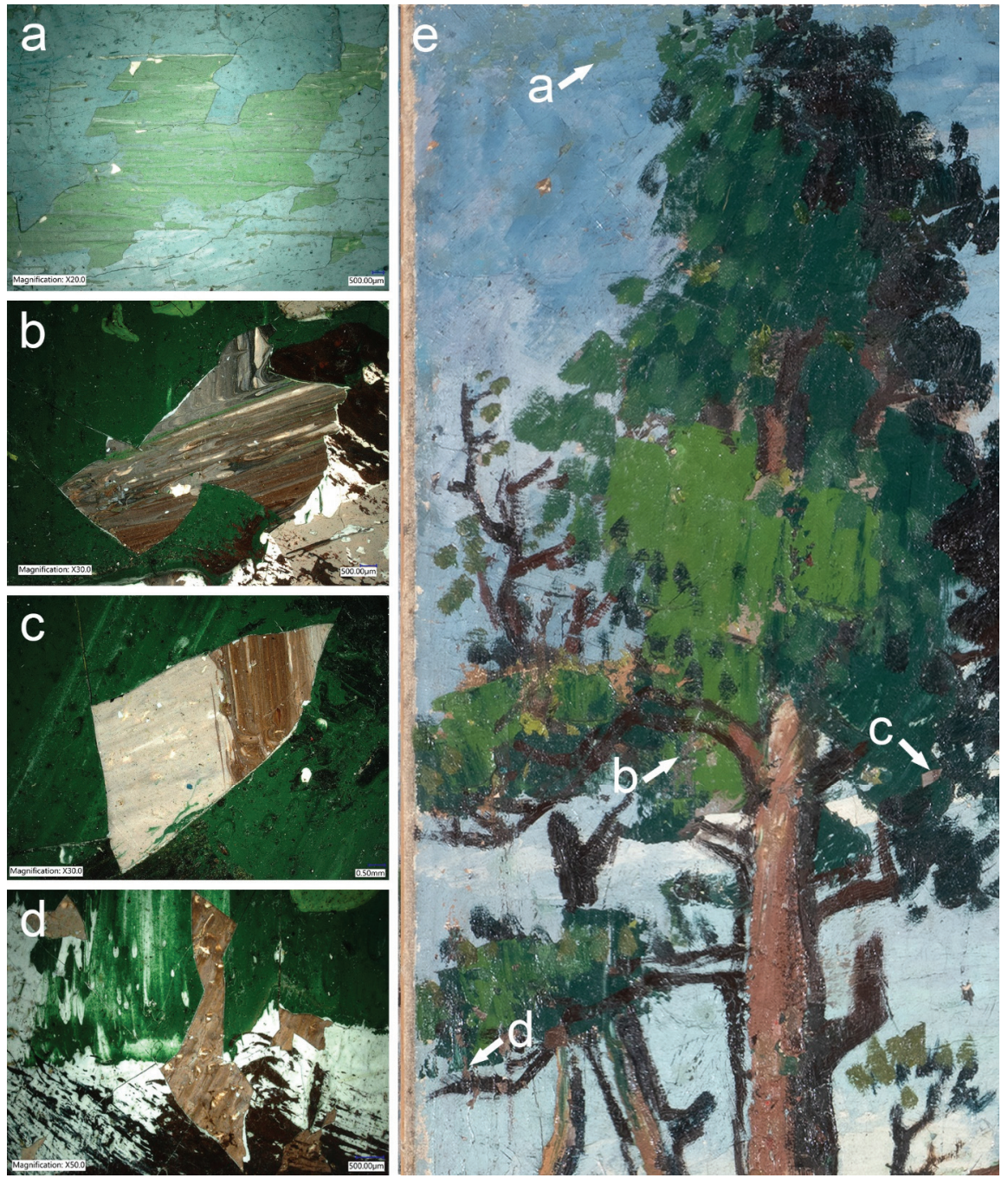

Figure 2. Digital microscope images of paint losses revealing a different paint scheme beneath Climbing the hill (a-d). The location of the losses (e).

donation in 2003 , so any alterations detected in the course of this study would be attributed to him. Thus, the initial supposition of falsification was refuted. Considering that both sets of signatures and dates are of Liu Kang's authorship, it was crucial to find out which set was applied first as this would be critical for dating Climbing the hill. Unexpectedly, an undated photograph of Climbing the hill, provided by the Liu family, documents that the painting was signed and dated 1948 or 1949 in the bottom-left corner (Figure 3e). The location and graphical form of the signature and date captured by the photograph are similar to those recorded with NIR of the investigated painting (Figure 3c, f). It is also important to note that the signature and date (1937) are not present in the bottom-right corner of the photographed painting (Figure 3e).

Additional comparisons of the bottom-left corner of the painting captured in the archival photograph with the same area of the current painting imaged in black-and-white, colour and IRFC photography, distinguished several green brushstrokes that had been applied later by the artist. These brushstrokes appeared purple in the IRFC, suggesting the use of $\mathrm{Cr}$ - and/or Co-containing green pigment applied on top of earlier painted greenery, also seen in the vicinity and represented in IRFC by blue and violet, suggesting a mixture composed mainly of Prussian blue (Figure 4).

Liu Kang's motivation to overpaint that area remains 

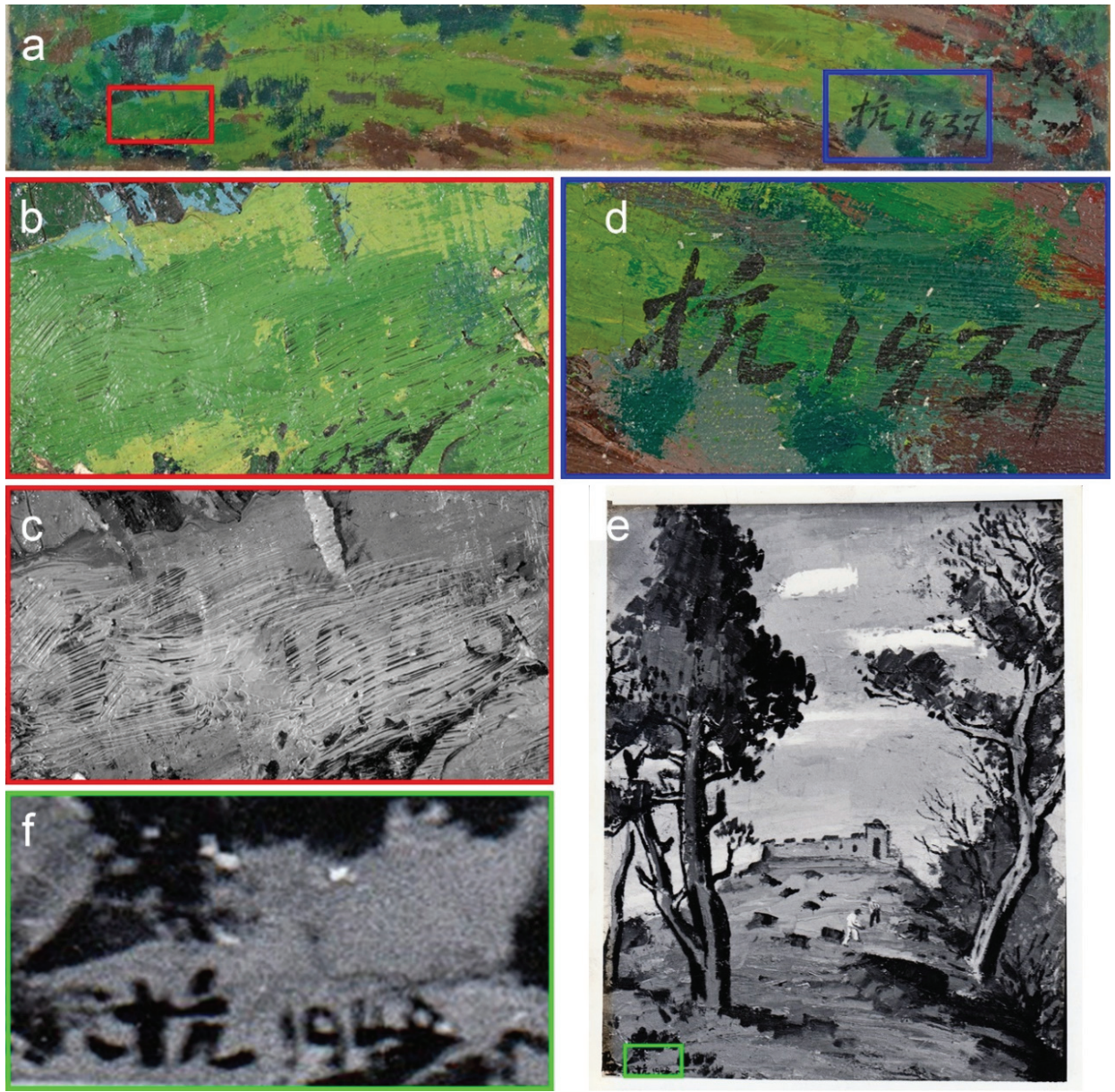

Figure 3. Details of Climbing the hill showing the: (a) positions of the overpainted signature with the date in the bottom-left corner (red rectangle) and existing signature with the date in the bottom-right corner (blue rectangle); (b) overpainted area of the signature and date photographed in VIS; (c) same area photographed in NIR; (d) existing signature photographed in VIS; (e) archival photograph of the Climbing the hill with the position of the original signature and date (green rectangle); (f) detail of the archival photograph of Climbing the hill showing the signature and date 1948 or 1949. Liu Kang Family Collection. Images courtesy of Liu family.

unknown as no evident paint losses were found that could have prompted such action. However, it could be speculated that the artist returned to the painting and decided to improve its aesthetics by adding new green hues covering the original signature and date as he did not have sale or exhibition plans for the work. It could be hypothesised that once the bottom-left corner was reworked, the painting remained unsigned and undated for a very long time, until the exhibition in 1993. The exhibition catalogue shows the painting in its current condition - with an overpainted bottom-left corner and a new signature and date (1937) in the bottom-right corner (Liu, 1993). Hence, a possible explanation is that in preparation for the exhibition, the artist was not able to recall the actual date of creation of the painting and unconsciously painted 1937.

Although the non-invasive imaging techniques supported by the archival photograph provided rationale of the mysterious hidden signature and date, a comparative investigation of the painting materials was conducted on View from St. John's Fort. The objective of the investigations was to reveal common patterns between both paintings, which would provide evidence to support the 1948 or 1949 dating of Climbing the hill, and shed light on its provenance. 


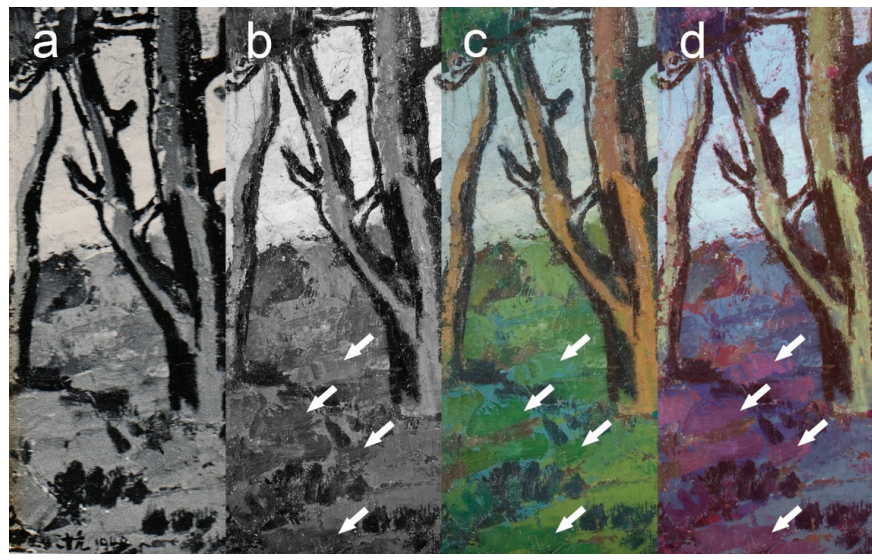

Figure 4. Detail of the bottom left corner of Climbing the hill from the archival photograph (a). Details showing the same area of the investigated painting imaged in: (b) black-and-white; (c) VIS; (d) IRFC. The white arrows indicated the areas of the overpaint.

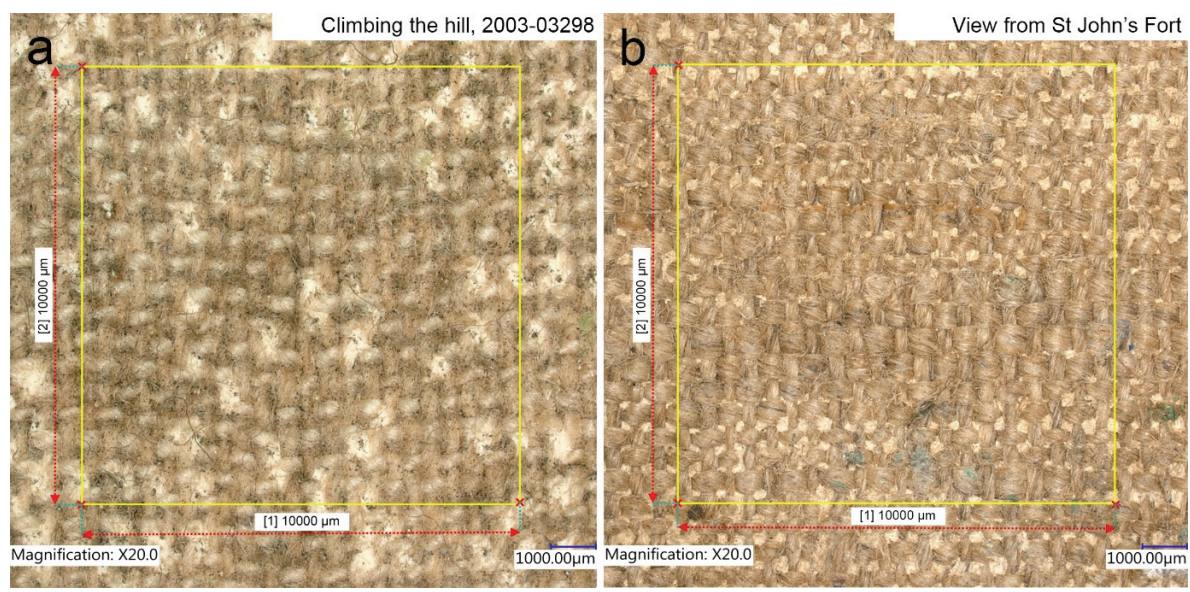

Figure 5. Photomicrographs of canvases from (a) Climbing the hill and (b) View from St. John's Fort.

\subsection{Auxiliary supports and characteristics of the} fabrics and grounds

The original auxiliary supports for both paintings were not preserved. Based on the visual assessment and according to the framer's label, Climbing the hill is stretched over the non-original plywood board, applied in 1992, while View from St. John's Fort remains unstretched. However, the presence of the irregularly distanced nail holes indicates that the paintings were originally stretched over stretchers or strainers. The dimensions of the paintings, measured from the painted edges, conform to common standards: Climbing the hill was created on portrait format number 20, and View from St. John's Fort adheres to portrait format number 10. It is known from earlier research that the artist tended to bend the rules when choosing painting support formats (Lizun et al., 2021b).

The canvases in both paintings were made in plain weave with Z-twisted threads of weft and warp. A thread count 19 $\times 17$ per cm was recorded for Climbing the hill and $20 \times 18$ per $\mathrm{cm}$ was recorded for View from St. John's Fort (Figure $5 \mathrm{a}, \mathrm{b})$. Although both canvases are characterised by similar structure, cotton was identified in Climbing the hill, by flattened fibres with internal helical convolutions. Linen was identified in View from St. John's Fort, by transverse markings, dislocations and pink, uneven stain after phloroglucinol test (Odegaard et al., 2000).

Judging by the presence of the ground on the tacking margins, both canvases were commercially prepared. 
Interestingly, the left and right tacking margins of View from St. John's Fort were covered with a paint layer that did not correlate to the present paint scheme. Moreover, the left tacking margin has painted digits " 931 " turned 180 degrees around with respect to the current composition, suggesting a relation to an underlying painting (Figure 6a, b). As Liu Kang did not have a habit of the numbering of his artworks, these digits could be a part of the 1931 date partially covered by the current painting. An unusual style of the characters prompted a comparison with other paintings by Liu Kang from the same period. A similar dynamic style of character "9" was found in Portrait of a man with his hat, Belgium (1930) from the Liu family collection (Figure 6c), while a simplified character "3" appeared in the Boat near the cliff

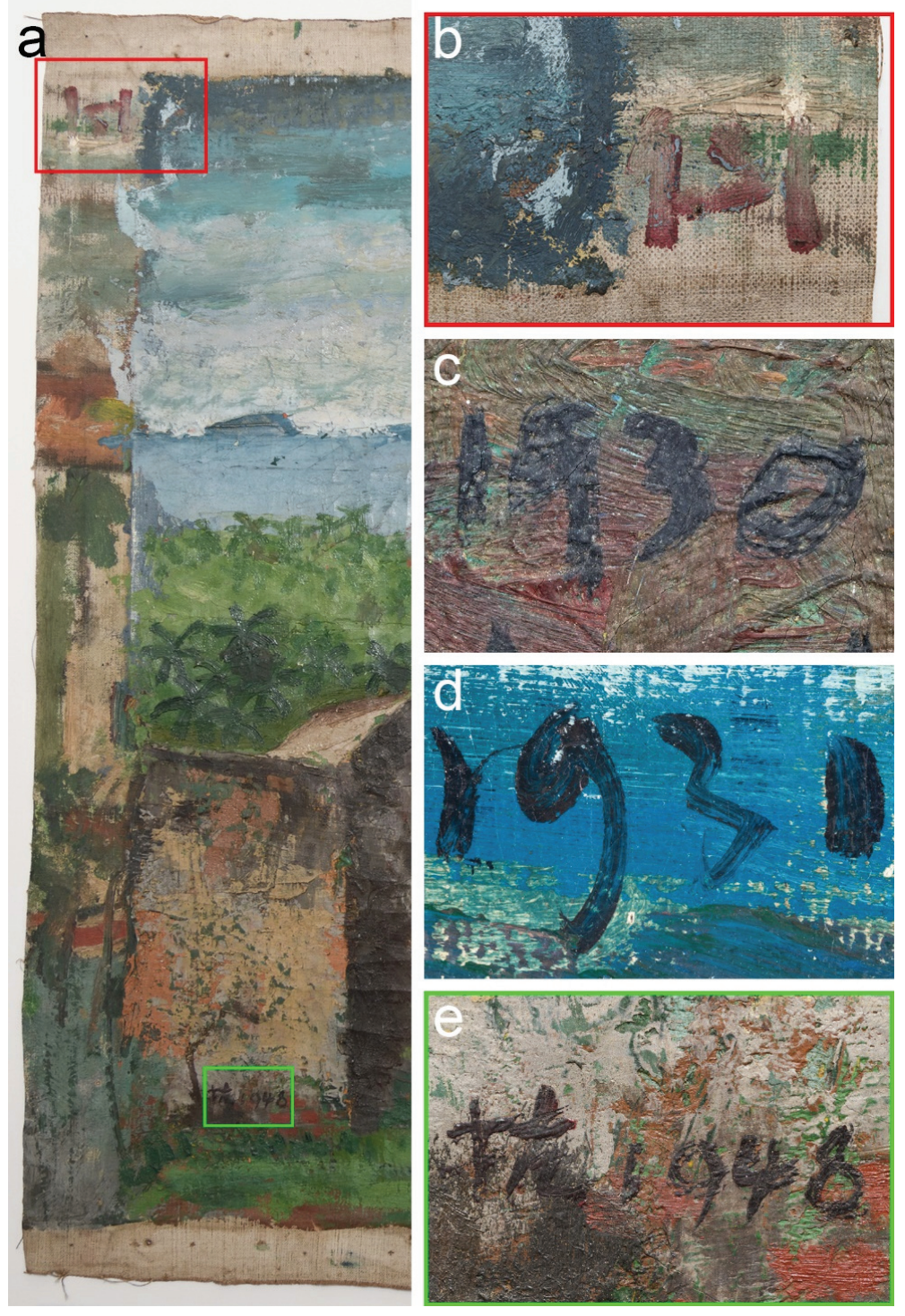

Figure 6. Detail of View from St. John's Fort and the underlying painting showing the position of the partially legible 1931 date (red rectangle) and 1948 date (green rectangle) (a). Detail showing the: (b) 1931 date, rotated at $180^{\circ}$, partially covered by the current composition of View from St. John's Fort; (c) 1930 date from Portrait of a man with his hat, Belgium from the Liu Kang Family Collection; (d) 1931 date from Boat near the cliff from the collection of National Gallery Singapore; (e) 1948 date from the View from St. John's Fort. Images courtesy of National Heritage Board and Liu family. 
(1931) from the NGS collection (Figure 6d). Thus, the collected information could support the hypothesis that the painting beneath was probably created in 1931 in Paris and then painted over in 1948. The presence of the paint layer of the earlier composition along the shoter edge of the canvas suggests that artist re-stretched the canvas over a smaller auxiliary support and then cut off an excess of the material.

As Liu Kang followed common size standards when choosing painting supports (Lizun et al., 2021b) and the underlying composition has a height of $46 \mathrm{~cm}$ and a width of $60 \mathrm{~cm}$ (after trimming), it is hypothesised that, the recycled artwork would have been painted in a landscape format of dimensions $46 \times 61 \mathrm{~cm}$ or a marine format with dimensions $46 \times 65 \mathrm{~cm}$ (Figure 7a, b). However, the latter format is very unlikely as it was not reported for any of Liu Kang's artworks from Paris (Lizun et al., 2021b).

The optical microscopy of the cross-sections extracted from Climbing the hill and View from St. John's Fort confirmed that they were created on the underlying compositions without the application of an intermediate ground. Based on the optical microscopy and SEM-BSE imaging, the grounds for the earlier compositions are pale white and single-layered. The ground layer for the painting beneath Climbing the hill (sample $\mathrm{cl}$ ) has a homogenous structure composed of lithopone (PW5, BaO5S2Zn2) and/or barium white (PW21, BaSO4) and zinc white (PW4, ZnO) with possible admixtures of lead white (PW1, C2H2O8Pb3) and titanium white (PW6, TiO2) (Figure 8a, b). The structure of the ground layer for the painting beneath View from St. John's Fort (sample v1) is characterised by distinct particles of chalk (PW18, CaCO3) mixed with lithopone and/or barium white and zinc white with trace amounts of titanium and lead whites (Figure 8c, d).

Considering that the underlying composition in View from St. John's Fort was created in 1931, a comparison of the canvas and ground characteristics was conducted with Liu Kang's paintings from the Paris period, and it confirmed a match with canvas type 2 and ground type 5 (Lizun et al., 2021b). Following on this lead, a similar comparison was done for the painting support of Climbing the hill as the current composition was created over the earlier painting. Cotton canvases of a similar density as the canvas from Climbing the hill were used predominantly by Liu Kang in Shanghai between 1933 and 1937, and they are classified as type 1 . The identified ground mixture would conform to a type 2, found in one Shanghai painting from 1936 (Lizun et al., 2021b).
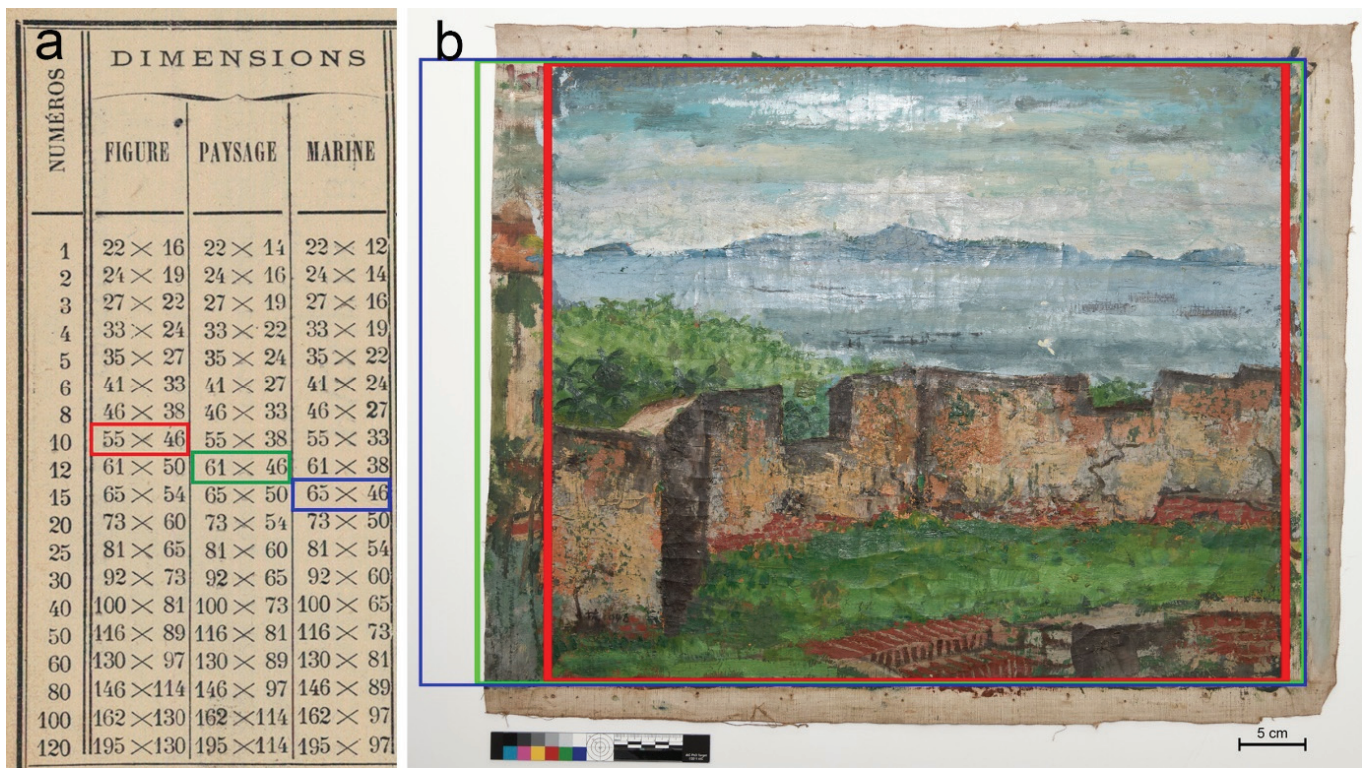

Figure 7. List of standard canvas formats from the 1929 Bourgeois Ainé catalogue (a) and View from St. John's Fort (b), with the dimensions of the current composition corresponding to portrait format number 10 (indicated in red), suggested dimensions of the underlying painting in landscape format number 12 (indicated in green) and suggested dimensions of the underlying painting in marine format number 15 (indicated in blue). 

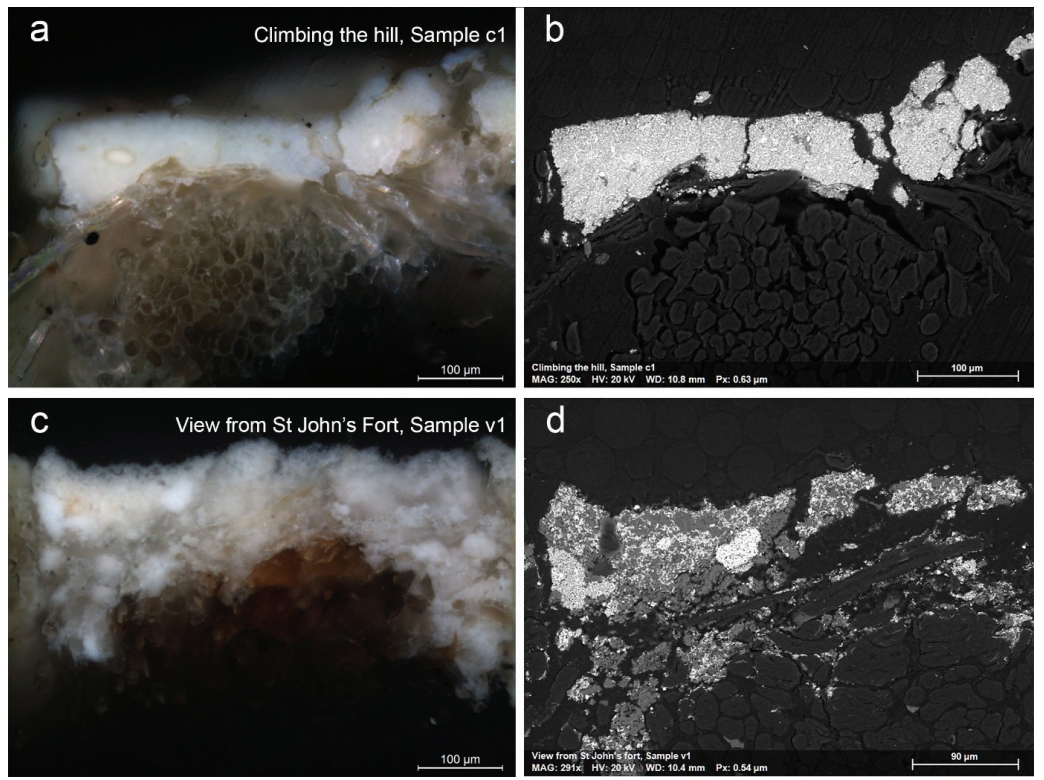

Figure 8. Microscopy and corresponding backscattered electron images (BSE) of cross-sections showing: the homogenous structure of ground layer extracted from: Climbing the hill ( $\mathrm{a}, \mathrm{b})$; structure of the ground layer characterised by large particles of chalk (visualised in dark grey in BSE image) from View from St. John's Fort (c, d).

\subsection{Art materials availability in Singapore in late 1940s}

These unexpected attributions of the canvas support to the Paris and Shanghai periods of Liu Kang's career sparked a curiosity about the rationale for reusing old paintings. Liu Kang's decision could have been impacted by the availability of art materials or his financial constraints, or both. The local art materials market and artist's practice were probably still affected by frequent disruptions to the distribution channels caused by the outbreak of the Second World War. On the other hand, another factor contributing to the scarcity of materials could have been the low local demand from art students and professional artists. In Singapore, the Nanyang Academy of Fine Arts, inaugurated in 1938, had to close during the Japanese Occupation (1942-1945); it was reopened in 1946. Additionally, the pre-war art community was torn apart and needed time to rebuild (Ong, 2007). As the new President (1946-1958) of the oldest and most influential Society of Chinese Artists, Liu Kang had good insights into the condition of the local art scene during the second half of the 1940s. His comments from his 1948 essay reveal the scale of damage caused by the war: "It is a miserable fact that there was a total of 12 large and small exhibitions in Singapore last year, with an average of one a month. This is miserable.
Of the 12 exhibitions, six were by European artists and five were by artists from China. Only one exhibition, the Seventh Annual National Day Art Exhibition, was organised by the local art community. This is regrettable (Liu, 2011)!"

His further comments in the same essay reveal the frustrations of an experienced artist who had spent several years in two cosmopolitan centres of the pre-war period: "Singapore is known as a metropolis with its population of one million people, of which at least 70 percent are Chinese. However, there are only a dozen artists, and the number of art organisations can be counted with the fingers of one hand. If we compare ourselves with four million people and 300,000 artists in Paris, the proportion is too pathetic and laughable (Liu, 2011)."

The poor condition of the local art community and its slow post-war recovery process undoubtedly influenced the demand for art materials, resulting in a lack of the specialised retailers in the post-war period. Nevertheless, archival search revealed that imported brands like Reeves \& Sons and Winsor \& Newton were distributed across the island through the stationery and book stores like E.J. Motiwalla \& Co., Peter Chong \& Coy (with many branches in Malaya), The Shanghai Book Company (with a branch in Kuala Lumpur), and Central Book Store (Figure 9) ("Central Book Store," 


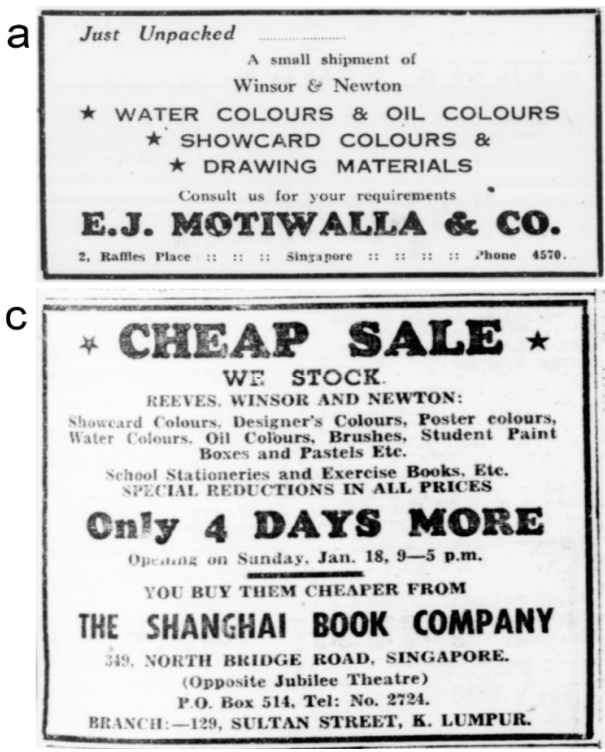

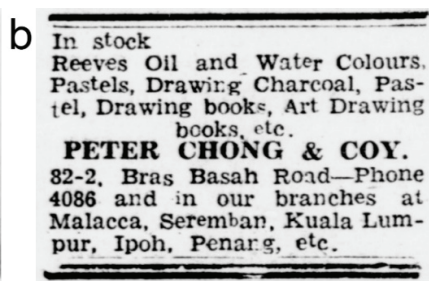

d

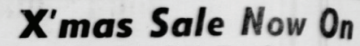

X'mas \& New Year Cards, Toys, Games, Trivh Decorations in Tinsel, Paper \& Glas. Secorations in Thel, Paper \& Glan \& Photo Albursts

Central Book Store

367, North Bridge Road, -ingapure

Figure 9. Advertisements by official retailers of art materials available in Singapore from 1947 to 1949: (a) E.J. Motiwalla \& Co.; (b) Peter Chong \& Coy; (c) The Shanghai Book Company; (d) Central Book Store.

1949; "E.J. Motiwalla \& Co," 1947; "Peter Chong \& Coy," 1947; "The Shanghai Book Company," 1948).

These few advertisements reveal that the availability of the art materials in Singapore in 1940s was impacted by stock limitations. They also do not mention canvas supports. Additionally, the art materials were also available from the Nanyang Book Company established in 1943 (with stores in Kuala Lumpur and Penang), and The Straits Commercial, established in 1947 in Singapore (Tse and Sloggett, 2008). Nevertheless, given that the prices of the imported materials were usually unattractive, Liu Kang might not have been interested in regular purchases as he was focused on providing for his young family (Liu, 1997). The harsh post-war economic realities did not stop him from painting but instead pushed him to the practice of reusing earlier artworks. In a 1981 interview, Liu Kang recalled that soon after his arrival to Malaya, his brother-in-law Chen Jen Hao joined him and brought some of Liu Kang's paintings from Shanghai (Mahbubani, 1981). In subsequent interviews from 1989 and 1996, Liu Kang said that he lost many of his works during the Japanese Occupation; however, he managed to find and recover some of them (Sabapathy, 1981; Sasitharan, 1989; Tan, 1997). Based on these accounts, it can be hypothesised that the canvas supports from the recovered artworks were good enough to be reused.

\subsection{Pigments}

The results of the pigment analyses are summarised in Tables 1 and 2 at the end of this section.

\subsubsection{Blue}

The IRFC imaging of both paintings showed that the most of the blue painted areas turned purple, suggesting the use of ultramarine and/or Co-containing blue (Figure 1b, d). The SEM-EDS measurements of samples c12 and v2 extracted from both paintings indicated a major use of ultramarine (PB29, Al6Na8O24S3Si6), confirmed with PLM (isotropic particles with low refractive index appear red with Chelsea filter). The intensity of the blue paint was modified by adding lead white extended with lithopone and/or barium white and zinc white. However, the bottom part of the sky of Climbing the hill appeared light blue in the IRFC image (Figure 1b), indicating a possible use of Prussian blue. SEM-EDS measurements of the samples (c13 and c17 layer 1) revealed mixtures of ultramarine and Prussian blue (PB27, $\mathrm{C} 18 \mathrm{Fe} 7 \mathrm{~N} 18)$. The latter was identified by the detection of a weak Fe-signal and PLM observation of dark blue isotropic particles, which appear dark green under a Chelsea filter and have a low refractive index. Prussian blue is present in the paint mixture at very low concentration, probably due to its 
high tinting strength (Berrie, 1997); however, that small admixture accounts for the blue hue of the area, recorded with the IRFC imaging.

\subsubsection{Green}

The comparison of green passages from both paintings unequivocally reveals that the artist produced a range of green hues in Climbing the hill to depict the upper branches of trees, whereas the greenery in View from St. John's Fort is executed with a limited definition of light effects and appears almost flat. The SEM-EDS analyses of light green areas revealed complex paint mixtures that appeared similar in both paintings (sample c14, v7). The detection of $\mathrm{Pb}, \mathrm{Ba}$, $\mathrm{Zn}, \mathrm{Cr}$ and $\mathrm{Fe}$ suggested the use of $\mathrm{Cr}$-containing green(s) and/or yellow(s), confirmed with PLM as viridian (PG18, $\mathrm{Cr} 2 \mathrm{H} 4 \mathrm{O} 5)$ by large and rough anisotropic particles with high refractive index and chrome yellow (PY34, PbCrO4) by anisotropic, rod-shaped particles with a high refractive index. However, strong $\mathrm{Pb}-, \mathrm{Ba}-$ and $\mathrm{Zn}$-signals can also be associated with lead white, lithopone and/or barium white and zinc white, used for the modification of green tint, whereas barium white may also appear as a commercial extender for lead white (Feller, 1986), viridian (Newman, 1997) and chrome yellow (Kühn and Curran, 1986). Based on the PLM analyses, the Fe-signal can be linked with Prussian blue, used by artists to modify the hue of green colours. Dark green paints have a similar elemental composition to the light greens; however, they are characterised by the absence of chrome yellow and an increased concentration of $\mathrm{Fe}$, indicating Prussian blue based on the PLM observation (samples c17 layer 2, v10). These findings are consistent with the IRFC imaging, as the blue and violet colours of the examined areas are notably determined by the presence of Prussian blue and viridian in the analysed paints (Figure 1b, d).

Certain green painted areas of both paintings are imaged purple in IRFC (Figure 1b, d), suggesting Cr- and/or Co-containing pigments. The evidence collected with a digital microscopy enabled to determine that these areas observed in View from St. John's Fort as well as from bottom-right corner of Climbing the hill relate to the earlier, underlying compositions intentionally exposed by the artists. The analyses of the paint sample (c24) from the bottom-right corner of the Climbing the hill confirmed a mixture composed predominantly of viridian and ultramarine applied directly on
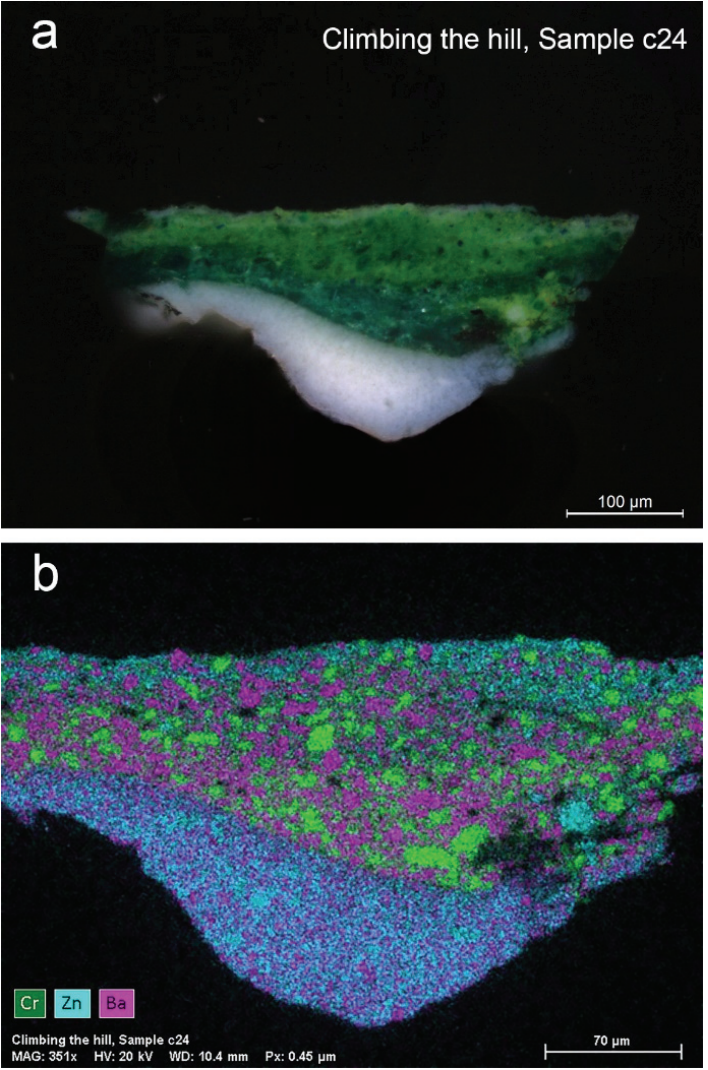

Figure 10. Microscopy image (a) and corresponding SEMEDS mapping of sample c24 of Climbing the hill (b). The SEM-EDS mapping shows the distribution of chromium $(\mathrm{Cr})$, zinc $(\mathrm{Zn})$ and barium $(\mathrm{Ba})$ in the paint sample.

a white ground, which is considered the original preparation of the canvas (Figure 10). Meanwhile, the purple imaged green patches from the bottom-left corner of the Climbing the hill correspond to latter alterations conducted by the artist.

\subsubsection{Red}

The optical microscopy and SEM-BSE images of the red paint samples extracted from both paintings (c21, v4) show a non-homogenous structure containing coarse particles of red, black and white, producing the same deep red colour. The SEM-EDS detection of Fe combined with the PLM observation of the anisotropic red particles with a high refractive index allowed the identification of red iron oxide (PR101, Fe2O3) as the principal component of the paint mixtures. A high concentration of lead white with extenders is noticeable in the sample c21 from Climbing the hill. Ca- 
and P-signals suggest the admixture of bone black (PBk9). The source of the other detected elements, such as $\mathrm{Mg}, \mathrm{Al}$, $\mathrm{Si}, \mathrm{K}, \mathrm{Ti}$ and $\mathrm{Sr}$, was challenging to pinpoint during the SEM-EDS measurements; however, these elements coincide naturally with iron oxides (Helwig, 2007).

\subsubsection{Yellow}

PLM and SEM-EDS analyses suggest that chrome yellow was the principal yellow used in the tiny yellow brushstrokes of Climbing the hill (sample c10). A weak Fe-signal recorded in this paint mixture was assigned to yellow iron oxide (PY43, FeOOH), later confirmed with PLM by anisotropic brown particles with a high refractive index (Figure 11a, b). Chrome yellow was also found earlier as an admixture of light green paints of Climbing the hill (sample c14). In contrast, the yellow paint used in View from St. John's Fort was primarily composed of yellow and red iron oxides with probable traces of Cr-containing yellow(s) that could have been added by the artist or paint manufacturer (Helwig, 2007; Kühn and Curran, 1986) (sample v5) (Figure 11c, d). The other elements present in both samples, such as $\mathrm{Pb}, \mathrm{Ba}, \mathrm{Zn}$, $\mathrm{Ca}$ and S, could correspond to lead white that is commercially admixed with barium white, zinc white and/or lithopone. $\mathrm{Ba}, \mathrm{Zn}$ and $\mathrm{Ca}$ elements in combination with $\mathrm{Cr}$ would account for the presence of other Cr-containing yellows not identified by PLM.

\subsubsection{White}

In both paintings, lead white appears to be the primary white pigment. It was found in the investigated colour mixtures as well as in the white painted areas (sample c18, v3). However, a consistent concomitant presence of $\mathrm{S}, \mathrm{Zn}$ and $\mathrm{Ba}$ suggests a commercial admixture of either zinc white and barium white and/or lithopone. A minor and trace concentration of Ti identified in both white paint samples may suggest a further modification of white paint with titanium white.
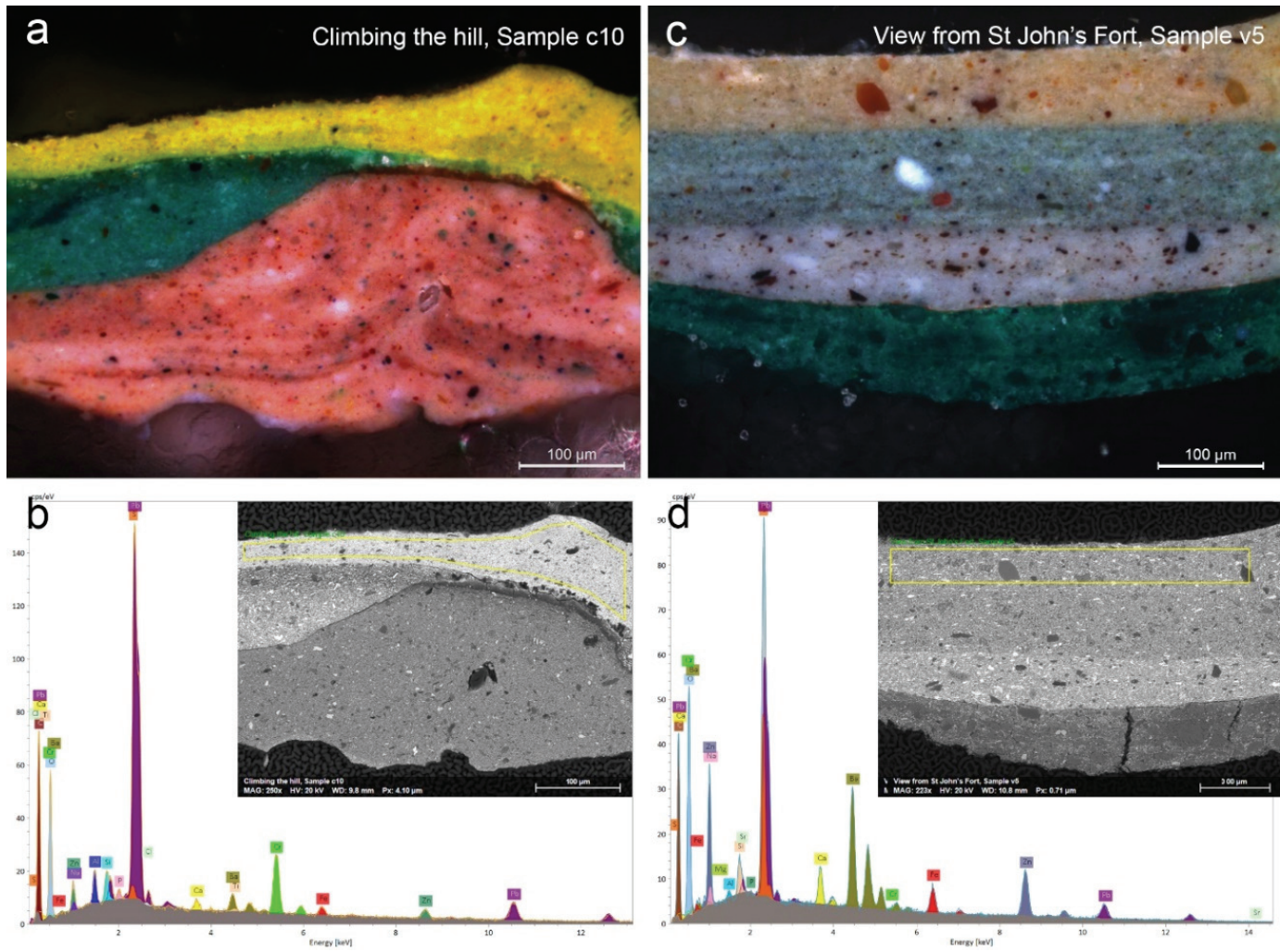

Figure 11. Microscopy images of cross-sections, corresponding SEM-EDS spectra of yellow layers, and inset backscattered electron (BSE) images with marked areas of analyses from sample c10 extracted from Climbing the hill (a, b), and from sample v5 extracted from View from St. John's Fort (c, d). 
Table 1. Overview of the materials identified in the paint samples extracted from the painting Climbing the hill

\begin{tabular}{|c|c|c|c|}
\hline & & & Climbing the hill \\
\hline Colour & Sample & SEM-EDS* detected elements & Possible PLM and SEM-EDS assignments \\
\hline $\begin{array}{l}\text { White } \\
\text { (ground layer) }\end{array}$ & $\mathrm{c} 1$ & $\begin{array}{l}C, O, \mathrm{Zn}, \mathrm{Ba}, \mathrm{Na}, \mathrm{S}, \mathrm{Ti} \\
\quad(\mathrm{Si}, \mathrm{Sr}, \mathrm{P}, \mathrm{Al}, \mathrm{Pb})\end{array}$ & $\begin{array}{l}\text { Lithopone and/or barium white and zinc white, titanium } \\
\text { white, traces of lead white }\end{array}$ \\
\hline Blue & $\mathrm{c} 12$ & $\begin{array}{l}C, \mathrm{~Pb}, \mathrm{O}, \mathrm{Zn}, \mathrm{Ba}, \mathrm{Na}, \mathrm{S}, \mathrm{Al} \\
\quad \mathrm{Si}, \mathrm{Ti},(\mathrm{Sr}, \mathrm{Ca}, \mathrm{P})\end{array}$ & $\begin{array}{l}\text { Lead white, lithopone and/or barium white and zinc white, } \\
\text { ultramarine, titanium white, possible traces of bone black }\end{array}$ \\
\hline Blue & $\mathrm{c} 13$ & $\begin{array}{l}\mathrm{Pb}, \mathrm{O}, \mathrm{Zn}, \mathrm{Ba}, \mathrm{Na}, \mathrm{S},(\mathrm{Ti}, \mathrm{Si} \\
\quad \mathrm{Cr}, \mathrm{Al}, \mathrm{Fe}, \mathrm{Ca}, \mathrm{Cl}, \mathrm{Mg})\end{array}$ & $\begin{array}{l}\text { Lead white, lithopone and/or barium white and zinc white, } \\
\text { ultramarine, viridian, Prussian blue }\end{array}$ \\
\hline Blue & $\begin{array}{l}\text { c17, } \\
\text { layer } 1\end{array}$ & $\begin{array}{l}P b, C, O, Z n, B a, \mathrm{Na}, \mathrm{S}, \mathrm{Ti} \\
\quad(\mathrm{Si}, \mathrm{Al}, \mathrm{Fe}, \mathrm{Sr}, \mathrm{P})\end{array}$ & $\begin{array}{l}\text { Lead white, lithopone and/or barium white and zinc white, } \\
\text { ultramarine, Prussian blue, titanium white, traces of bone black }\end{array}$ \\
\hline Green & $\mathrm{c} 14$ & $\begin{array}{l}\mathrm{Pb}, O, C, \mathrm{Ba}, \mathrm{Zn}, \mathrm{Cr}, \mathrm{Na}, \mathrm{S} \\
(\mathrm{Ti}, \mathrm{Al}, \mathrm{Si}, \mathrm{P}, \mathrm{Fe})\end{array}$ & $\begin{array}{l}\text { Lead white, lithopone and/or barium white and zinc white, } \\
\text { viridian, chrome yellow, Prussian blue }\end{array}$ \\
\hline Green & $\begin{array}{l}\mathrm{c} 17 \\
\text { layer } 2\end{array}$ & $\begin{array}{l}C, O, B a, \mathrm{~Pb}, \mathrm{~S}, \mathrm{Fe}, \mathrm{Cr}, \mathrm{Ti} \\
\mathrm{Zn},(\mathrm{Sr}, \mathrm{Si}, \mathrm{Na}, \mathrm{Al}, \mathrm{Ca}, \mathrm{P})\end{array}$ & $\begin{array}{l}\text { Lead white, lithopone and/or barium white and zinc white, } \\
\text { Prussian blue, viridian, titanium white }\end{array}$ \\
\hline Green & $\mathrm{c} 24$ & $\begin{array}{l}O, C, B a, C r, \mathrm{~S}, \mathrm{Zn}, \mathrm{Pb}, \mathrm{Ti} \\
\quad \mathrm{Na},(\mathrm{Sr}, \mathrm{Ca}, \mathrm{Si}, \mathrm{Al}, \mathrm{Fe})\end{array}$ & $\begin{array}{l}\text { Viridian, lithopone and/or barium white and zinc white, lead } \\
\text { white, titanium white, ultramarine, yellow iron oxide }\end{array}$ \\
\hline Red & $\mathrm{c} 21$ & $\begin{array}{l}O, C, P b, \mathrm{Ba}, \mathrm{Zn}, \mathrm{Fe}, \mathrm{S}, \mathrm{Na} \\
\mathrm{Ca}, \mathrm{Si}, \mathrm{Ti},(\mathrm{Al}, \mathrm{P}, \mathrm{Sr})\end{array}$ & $\begin{array}{l}\text { Lead white, lithopone and/or barium white and zinc white, } \\
\text { red iron oxide, bone black }\end{array}$ \\
\hline Yellow & $\mathrm{c} 10$ & $\begin{array}{l}\mathrm{Pb}, \mathrm{C}, \mathrm{O}, \mathrm{Cr}, \mathrm{Ba}, \mathrm{Zn}, \mathrm{Al}, \mathrm{Fe} \\
\quad(\mathrm{Si}, \mathrm{Na}, \mathrm{Ca}, \mathrm{S}, \mathrm{P}, \mathrm{Ti}, \mathrm{Cl})\end{array}$ & $\begin{array}{l}\text { Chrome yellow and lead white, lithopone and/or barium white } \\
\text { and zinc white, yellow iron oxide }\end{array}$ \\
\hline White & $\mathrm{c} 18$ & $\begin{array}{c}P b, O, C, B a, Z n, \mathrm{Na}, \mathrm{S}, \mathrm{Ti}, \\
(\mathrm{Al}, \mathrm{Si}, \mathrm{P})\end{array}$ & $\begin{array}{l}\text { Lead white, lithopone and/or barium white and zinc white, } \\
\text { titanium white }\end{array}$ \\
\hline
\end{tabular}

*Major elements are given in italic, minor elements in plain type and trace elements in brackets.

Table 2. Overview of the materials identified in the paint samples extracted from the painting View from St. John's Fort

\begin{tabular}{|c|c|c|c|}
\hline \multicolumn{4}{|c|}{ View from St. John's Fort } \\
\hline Colour & Sample & SEM-EDS* detected elements & Possible PLM and SEM-EDS assignments \\
\hline $\begin{array}{l}\text { White } \\
\text { (ground layer) }\end{array}$ & $\mathrm{v} 1$ & $\begin{array}{l}C, O, B a, C a, \mathrm{Zn}, \mathrm{S} \\
(\mathrm{Si}, \mathrm{Na}, \mathrm{Ti}, \mathrm{Pb})\end{array}$ & $\begin{array}{l}\text { Lithopone and/or barium white and zinc white, calcium } \\
\text { carbonate, traces of titanium white and lead white }\end{array}$ \\
\hline Blue & $\mathrm{v} 2$ & $\begin{array}{l}C, O, P b, B a, Z n, \mathrm{~S}, \mathrm{Na}, \mathrm{Al} \\
\quad \mathrm{Si},(\mathrm{Cr}, \mathrm{Ca}, \mathrm{Mg}, \mathrm{Ti})\end{array}$ & $\begin{array}{l}\text { Lead white, lithopone and/or barium white and zinc white, } \\
\text { ultramarine, traces of viridian }\end{array}$ \\
\hline Green & v7 & $\begin{array}{l}C, P b, O, B a, Z n, \mathrm{~S}, \mathrm{Na}, \mathrm{Cr} \\
(\mathrm{Al}, \mathrm{Si}, \mathrm{Fe}, \mathrm{Mg}, \mathrm{Cl}, \mathrm{Ca})\end{array}$ & $\begin{array}{l}\text { Lead white, lithopone and/or barium white and zinc white, } \\
\text { viridian, chrome yellow, Prussian blue }\end{array}$ \\
\hline Green & $\mathrm{v} 10$ & $\begin{array}{l}C, O, B a, P b, \mathrm{Zn}, \mathrm{S},(\mathrm{Na}, \mathrm{Fe} \\
\quad \mathrm{Cr}, \mathrm{Sr}, \mathrm{Ca}, \mathrm{Ti}, \mathrm{Al}, \mathrm{Cl}, \mathrm{Si})\end{array}$ & $\begin{array}{l}\text { Lead white, lithopone and/or barium white and zinc white, } \\
\text { Prussian blue, traces of viridian }\end{array}$ \\
\hline Red & $\mathrm{v} 4$ & $\begin{array}{l}O, \mathrm{Fe}, \mathrm{Ca}, \mathrm{C}, \mathrm{Si}, \mathrm{Ba},(\mathrm{Al}, \mathrm{S} \\
\quad \mathrm{Pb}, \mathrm{Mg}, \mathrm{Zn}, \mathrm{K}, \mathrm{Sr}, \mathrm{Ti}, \mathrm{P})\end{array}$ & $\begin{array}{l}\text { Red iron oxide, lithopone and/or barium white and zinc white, } \\
\text { lead white, bone black }\end{array}$ \\
\hline Yellow & v5 & $\begin{array}{l}O, C, P b, B a, \mathrm{Zn}, \mathrm{S}, \mathrm{Fe}, \mathrm{Ca} \\
\mathrm{Na},(\mathrm{Si}, \mathrm{Al}, \mathrm{Mg}, \mathrm{Sr}, \mathrm{Cr}, \mathrm{P})\end{array}$ & $\begin{array}{l}\text { Lead white, lithopone and/or barium white and zinc white, } \\
\text { yellow and red iron oxide, possible chrome yellow or other } \\
\text { Cr-containing yellow(s), bone black }\end{array}$ \\
\hline White & v3 & $\begin{array}{l}C, B a, O, \mathrm{~S}, \mathrm{Zn}, \mathrm{Ca}, \mathrm{Pb}, \mathrm{Na} \\
\text { (Ti, Sr, Si, Al, Cr) }\end{array}$ & $\begin{array}{l}\text { Lead white, lithopone and/or barium white and zinc white, } \\
\text { titanium white }\end{array}$ \\
\hline
\end{tabular}

*Major elements are given in italic, minor elements in plain type and trace elements in brackets. 


\subsection{Execution of the paintings}

The technical evidence collected from both paintings shows that Liu Kang reused his earlier artworks. He painted directly on the previous compositions without applying an intermediate ground layer. Although NIR did not reveal any preparatory sketches, an archival search provided an undated pencil drawing that could be a study conducted prior to his painting Climbing the hill (Figure 12a, b). The rapidly executed drawing expressively captures the view of the hill by means of free-flowing lines with a minimum of shading and gradation. Moreover, two undated black-and-white photographs of the hill, taken by the artist, seem to complement the study with documentary precision (Figure 12c, d). Considering that the drawing and photographs are consistent with the time that painting was created, they may be indicative of the artist's search for the composition and sources of inspiration. The photographs could also have been used as references for developing the painting upon the artist's return to Singapore. Nevertheless, these supplementary media demonstrate the process of the creation of a painting, from the initial study to the completed work.

With regard to the painting technique, both artworks were executed rapidly with a combination of a palette knife and brush. Palette knife touches are more evident in Climbing the hill as the artist used this tool for quickly covering the surface with colour. Meanwhile, the brush was used for more detailed and descriptive work. This technique significantly reduced
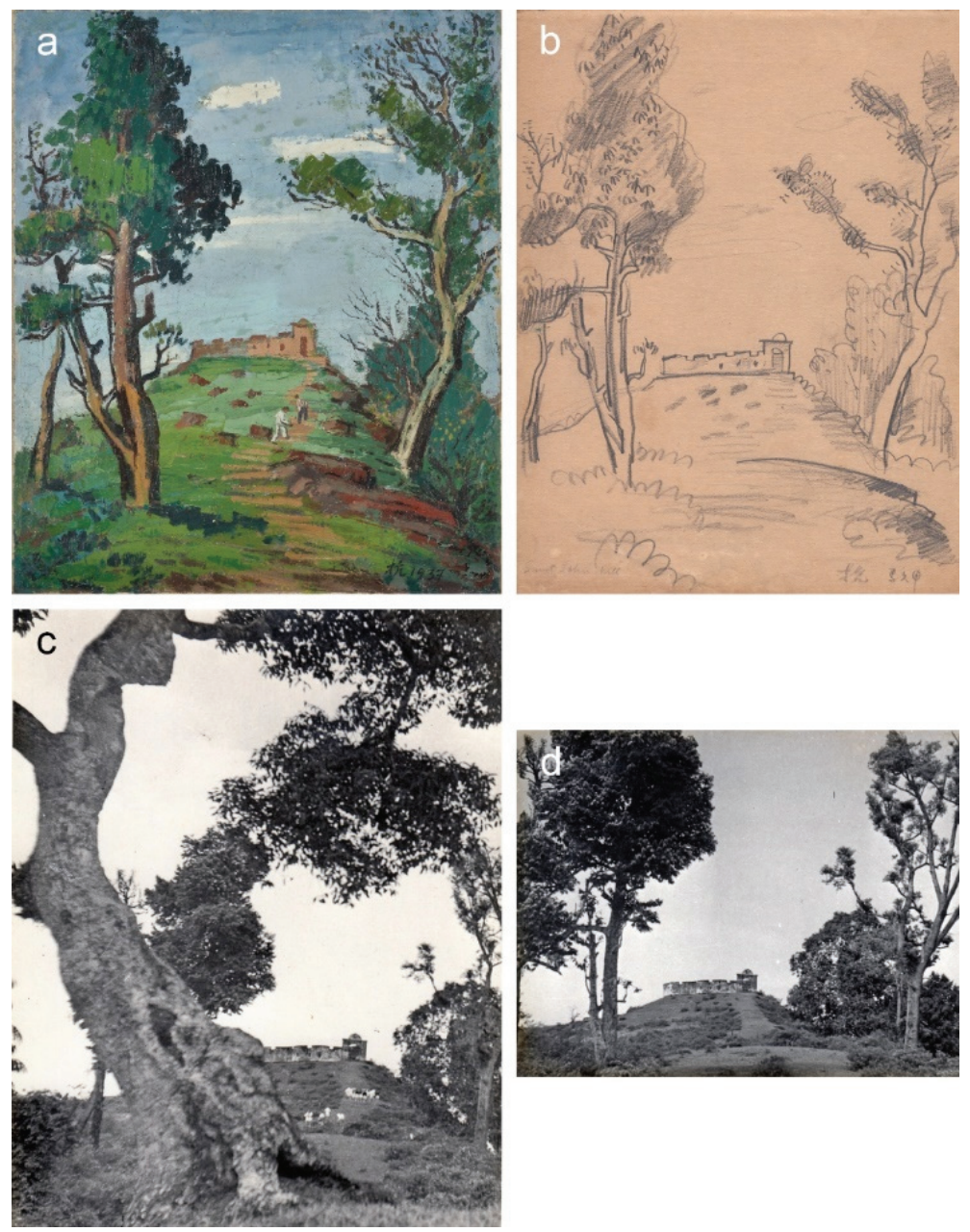

Figure 12. Image of (a) Climbing the hill. Image of Liu Kang's: (b) pencil drawing; (c, d) archival photographs of the studied scene. Liu Kang Family Collection. Images courtesy of Liu family. 

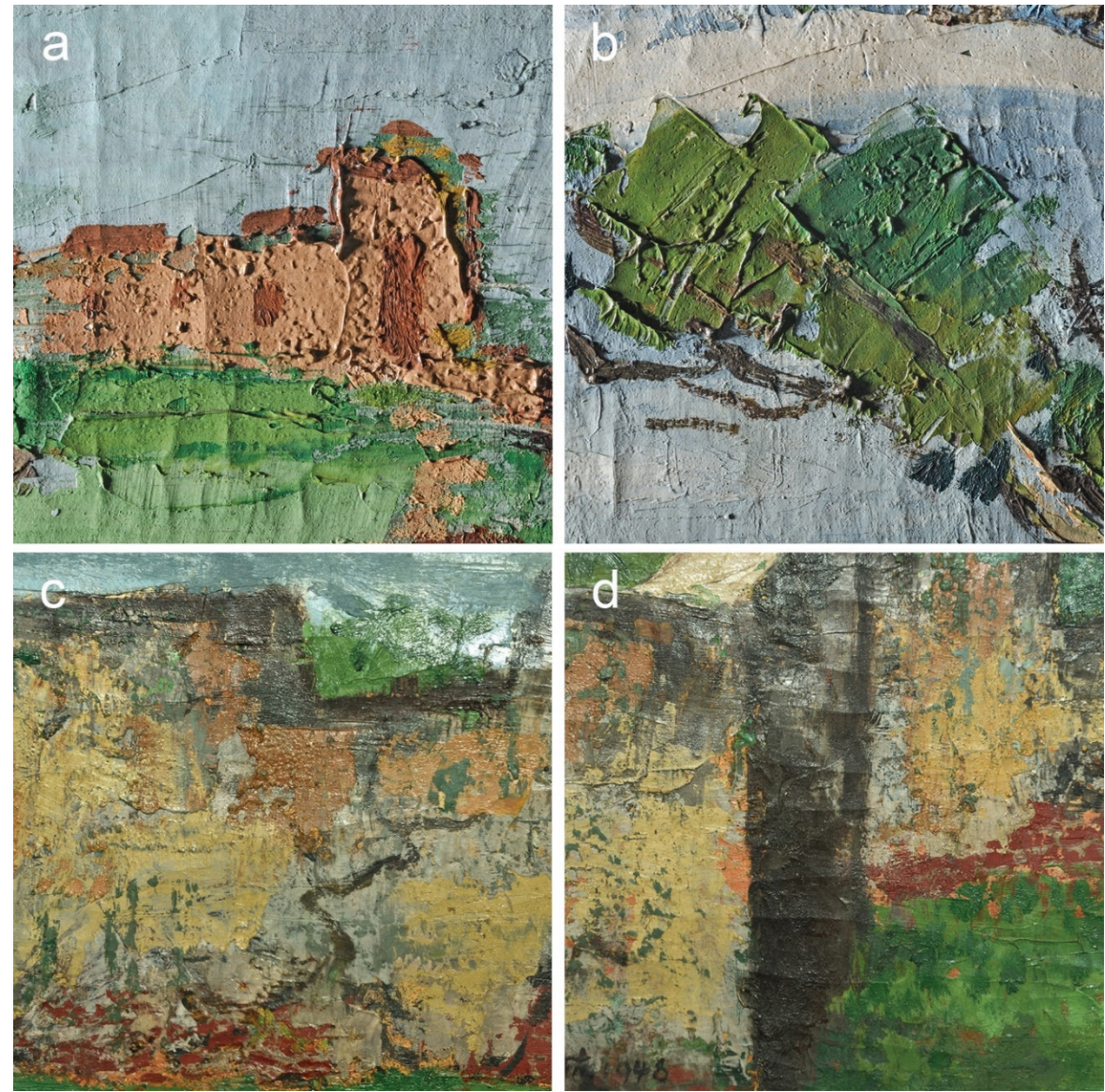

Figure 13. Details of Climbing the hill illustrating palette knife paint application completed with minor brush strokes (a, b). Details of View from St. John's Fort illustrating a combination of palette knife and brush paint application found in the area of fort wall (c, d).

the time required to complete the work (Figure 13a, b). In View from St. John's Fort, the brush played a major role while palette knife paint application was used only for the execution of the fort's wall (Figure 13c, d). Based on these observations it is clearly evident that, the painting technique of two artworks demonstrates some differences despite they have been created the same year. This may reflect Liu Kang's free approach to the technique in support of the artistic expression.

\section{CONCLUSION}

The multidisciplinary approach - combining analytical and historical data - enabled the dating of Climbing the hill to be approximated as 1948 or 1949 rather than 1937. Moreover, the archival photographs and drawing shed light on the artist's painting process. Digital microscopy proved to be effective in evidencing the presence of an earlier composition under the current paint layer, while IRFC imaging was crucial in the tentative identification of pigments and selection of sampling areas. A comparative technical study of Climbing the hill and View from St. John's Fort gives insights into the material preferences and also unveils a few converging features. Both paintings were created directly over the earlier compositions without an intermediate ground layer. However, the structure of the canvas and the ground composition for the painting beneath Climbing the hill exhibit features consistent with Liu Kang's Shanghai period (1933-1397), while the canvas and ground layer for the painting beneath View from St. John's Fort have features typical of the Paris period (1929-1932), which is further supported by the partially visible date 1931 . This discovery 
may reflect the scarcity of the painting materials available to the artist in 1948 or his financial constraints, which forced him to reuse his earlier compositions in order to continue artistic career. With regard to the pigments, the range of colours used by the artist in Climbing the hill and View from St. John's Fort is restricted; however, the range is adequate for the painted scenes, which are dominated by blue, green and yellow colours. Hence, Liu Kang made an extensive use of ultramarine, Prussian blue, viridian, chrome yellow, yellow, and red iron oxides and lead white. Judging from the similar dating, subject matter, and involvement of nearly identical pigment mixtures in both artworks, it is hypothesised that there is a strong relationship between the paintings and that they were created by Liu Kang at approximately the same time.

However, the interpretation of the collected data highlighted some areas that should be addressed in the further research. As the XRR of Climbing the hill did not produce sufficient information, the visualisation of the hidden composition could be achieved with MA-XRF. This technique could also guide potential sampling for the in-depth study of the pigments used in the creation of the hidden artwork. Additionally, to improve the comparison of the pigments used by the artist in Climbing the hill and View from St. John's Fort a more extensive study using a range of vibrational spectroscopic techniques is required.

Ultimately, the results obtained from the investigation of both paintings may add to the growing body of knowledge about Liu Kang. Nevertheless, a more extensive study of his works created after the war will contribute further to a better overview of his painting materials and technique.

\section{ACKNOWLEDGEMENTS}

The author would like to acknowledge the National Gallery Singapore for allowing the investigation of the painting Climbing the hill; the Heritage Conservation Centre for supporting this study; Gretchen Liu for allowing the investigation of the painting View from St. John's Fort and for sharing the artist's archives; Kenneth Yeo Chye Whatt (Principal Radiographer from the Division of Radiological Sciences at Singapore General Hospital) and Dr Steven Wong Bak Siew (Head and Senior Consultant from the Department of Radiology at Sengkang General Hospital) for facilitating the X-ray radiography. The author wishes to thank Hanna Szczepanowska PhD at West Virginia University for her comments, which were essential for making further improvements to the paper. The author also would like to thank to the reviewers for their comments and hints related to the quality of the article.

\section{REFERENCES}

Berrie, B.H., 1997, Prussian blue. In: West FitzHugh, E. (ed.), Artists' pigments: a handbook of their history and characteristics (Vol. 3). National Gallery of Art, Washington, 196.

Central Book Store, 1949, Dec 10. The Singapore Free Press, 2. https://eresources.nlb.gov.sg/newspapers/digitised/ article/freepress 19491210-1.2.34.2 (March 8, 2021)

Cosentino, A., 2014, Identification of pigments by multispectral imaging; a flowchart method. Heritage Science, 2(1), 12.

Cosentino, A., 2015, Practical notes on ultraviolet technical photography for art examination. Conservar Património, (21), 53-62.

Cosentino, A., 2016, Infrared technical photography for art examination. e-Preservation Science, 13, 1-6.

Croizier, R., 1993, Post-impressionists in pre-war Shanghai: the Juelanshe (Storm Society) and the fate of modernism in republican Shanghai. In: Clark, J. (ed.), Modernity in Asian art. Wild Peony, Broadway, NSW, Australia, 152.

E.J. Motiwalla \& Co, 1947, Feb 21. The Straits Times, 5. http://eresources.nlb.gov.sg/newspapers/Digitised/Article/ straitstimes19470221-1.2.60.1 (March 8, 2021)

Feller, R.L., 1986, Barium sulfate - natural and synthetic. In: Feller, R. L. (ed.), Artists' pigments: a handbook of their history and characteristics (Vol. 1). National Gallery of Art, Washington, 47.

Helwig, K., 2007, Iron oxide pigments: natural and synthetic. In: Berrie, B. H. (ed.), Artists' pigments: a handbook of their history and characteristics (Vol. 4). National Gallery of Art, Washington, 64, 65, 73, 88.

Kühn, H. and Curran, M., 1986, Chrome yellow and other chromate pigments. In: Feller, R. L. (ed.), Artists' pigments: a handbook of their history and characteristics (Vol. 1). National Gallery of Art, Washington, 190, 196.

Kwok, K.C., 2000, Journeys: Liu Kang and his art $=$ Yi cheng: Liu Kang qi ren qi yi. National Arts Council, Singapore, 49.

Liu, K., 1993, The world of Liu Kang 1993. National Museum Art Gallery, Singapore, 29.

Liu, K., 1997, Liu Kang at 87. In:National Arts Council, 
National Heritage Board, Singapore, 18, 19.

Liu, K., 2011, Commemorative post-war art festival. In: Siew, S. (ed.), Liu Kang: essays on art \& culture. National Art Gallery, Singapore, 28, 29.

Lizun, D., 2020, A preliminary study of Liu Kang's palette and the discovery and interpretation of hidden paint layers. Heritage Science, 8, 1-18.

Lizun, D., Kurkiewicz, T. and Szczupak, B., 2021a, Exploring Liu Kang's Paris practice (1929-1932): insight into painting materials and technique. Heritage, 4(2), 828-863.

Lizun, D., Kurkiewicz, T. and Szczupak, B., 2021b, Technical examination of Liu Kang's Paris and Shanghai painting supports (1929-1937). Heritage Science, 9, 1-32.

Lizun, D., Szroeder, P., Kurkiewicz, T. and Szczupak, B., 2021c, Examination of painting technique and materials of Liu Kang's Seafood and hidden self-portrait. International Journal of Conservation Science, 12(1), 3-26.

Mactaggart, P. and Mactaggart, A., 1998, A pigment microscopist's notebook. Mactaggart, Chard.

Mahbubani, G., 1981, Dec 1. Journey of a pioneer artist. The Straits Times, 1. http://eresources.nlb.gov.sg/newspapers/ Digitised/Article/straitstimes19811201-1.2.138.2 (March 8, 2021)

Newman, R., 1997. Chromium oxide and hydrated chromium oxide. In: West FitzHugh, E. (ed.), Artists' pigments: a handbook of their history and characteristics (Vol. 3). National Gallery of Art, Washington, 281.

Odegaard, N., Carroll, S. and Zimmt, W.S., 2000, Material characterization tests for objects of art and archaeology Archetype publications, London, 156, 157.

Ong, Z.M., 2007, The History of Nanyang Academy of Fine Arts (1938-1990). (Master Master's thesis), National University of Singapore, Singapore, 63, 64. https://scholar bank.nus.edu.sg/handle/10635/15776 (March 8, 2021)
Peter Chong \& Coy, 1947, Aug 5. Malaya Tribune, 2. http://eresources.nlb.gov.sg/newspapers/Digitised/Article/ maltribune19470805-1.2.26.3 (March 8, 2021)

Sabapathy, T.K., 1981, April 14. Romance of art. The Straits Times, 5. http://eresources.nlb.gov.sg/newspapers/ Digitised/Article/straitstimes 19810414-1.2.131.10.1. (March 8, 2021)

Sasitharan, T., 1989, Jul 21. Coloured by Time. The Straits Times, 1. http://eresources.nlb.gov.sg/newspapers/Digitised/ Article/straitstimes19890721-1.2.61.2 (March 8, 2021)

Schalm, O., Vanbiervliet, L., Willems, P. and de Schepper, P., 2014, Radiography of paintings: limitations of transmission radiography and exploration of emission radiography using phosphor imaging plates. Studies in Conservation, 59(1), 10-23.

The Shanghai Book Company, 1948, Jan 16. The Singapore Free Press, 5. http://eresources.nlb.gov.sg/newspapers/ digitised/article/freepress 19480116-1.2.37.1 (March 8, 2021)

Tan, M.K., 1997, The evolution of the Nanyang art style: a study in the search for an artistic identity in Singapore, 1930-1960. (Master of Philosophy in Humanities Master's thesis), Hong Kong University of Science and Technology, Hong Kong, 51. http://hdl.handle.net/1783. 1/4804 (March 8, 2021)

Tse, N. and Sloggett, R., 2008, Southeast Asian oil paintings: supports and preparatory layers. In: Townsend, J., Doherty, T., Heydenreich, G. and Ridge, J. (eds.), Preparation for painting: the artist's choice and its consequence. Archetype Publications, London, 153.

Warda, J., Frey, F., Heller, D., Kushel, D., Vitale, T. and Weaver, G., 2011, The AIC guide to digital photography and conservation documentation. American Institute for Conservation of Historic and Artistic Works, Washington, D.C. 